\title{
Ethical Maturity Scores of Future Arab Business Leaders Based on Gender, Age, Seniority, Management, and Ethics Training
}

\author{
Abdul R. Abu Bakar, ${ }^{1, *}$, Bahaudin G. Mujtaba ${ }^{2}$ and Ahmed Medjedel $^{3}$ \\ ${ }^{1}$ College of Business Administration, Prince Sultan University, Saudi Arabia; ${ }^{2}$ Nova Southeastern University, 3301 Col- \\ lege Avenue, Fort Lauderdale, FL. 33314-7796, USA; ${ }^{3}$ College of Business Administration, Taibah University, Madina, \\ Saudi Arabia
}

\begin{abstract}
The financial collapse of many prominent institutions over the past six years has highlighted the importance of morality and ethics in the workplace. Recent evidence has demonstrated that ethics is an important topic for all working adults and students who will soon join the workforce. As such, using the personal business ethics scores (PBES) survey, this study tests 164 students' demographic profiles and 'ethical exposure' in Saudi Arabia. Using factor analysis, analysis of variance, and regression analysis with the sample data, this study highlights a statistically significant relationship between legal knowledge and ethical maturity among Arabs in this research. Other predictors proposed in this study such as gender, age, seniority, management experience, and ethical exposure through courses, seminars or work experience did not show any significant effects towards ethical maturity. Limitations are presented along with implications for business school faculty and deans as they prepare future managers to become morally mature leaders in the workplace.
\end{abstract}

Keywords: Arab students, business ethics, ethics training, ethical maturity, Madinah, PBES, Saudi Arabia.

\section{INTRODUCTION}

The ethical decision-making processes of students and working adults have been studied often by researchers over the past few decades [1-6]. However, there is little empirical work investigating differences in ethical decision-making among Arab students based on various demographic variables. Therefore, examining the differences and similarities among Arab students who are planning to enter the workforce is the focus of this study.

The Western world's financial crisis of the past decades demonstrates irresponsible lending, lack of transparency and ethical failures among senior business experts [7-9]. Naturally, academicians, politicians and corporate managers are concerned about the impact of these negative behaviors on the future of their firms, companies and society in general $[10,11]$. Ethical decision making, especially for managers and leaders of every sector, is important since it influence the reputation as well as the performance of a company and an economy $[12,13]$. Sadly, there appears to be a huge gap or discrepancy between what business leaders say they would do and what they actually have done over the past few decades [14]. The business world in Saudi Arabia is currently facing many ethical issues, but like most other places and industries, it is receiving little attention from business ethics scholars [15].

The main research question for this study is as follows: Are there differences in ethical decision making among Arabs based on various demographic variables such as age,

*Address correspondence to this author at the College of Business Administration, Prince Sultan University, Saudi Arabia;

Tel: +9661-494-8926 Fax: +9661-454-8316;

E-mails:drrahimbakar@gmail.com; Aabubakar@psu.edu.sa gender, seniority, management experience, legal knowledge, ethics training, and sensitivity training?

The structure of this paper is as follows. We first review literature on the ethical decision making of students. In the next section, we describe the empirical study used to test hypotheses. We end the paper with findings, results, and a conclusion section.

\section{ETHICS AND EDUCATION}

It has been argued that many students do not receive sufficient ethics education and moral leadership styles [16, 17]. However, attitudes toward ethics education are changing [2]. Academic institutions and professional bodies are of the opinion that ethics should be taught as a dedicated unit within professional programmes and degree curriculums [18-20]. Ethics education and initiatives will support individuals in making decisions when faced with ethical dilemmas and ethical challenges [21, 22]. As the need for business ethics education becomes more essential, the degree to which it takes place in college curriculums and corporate training, and whether the effect is positive, are still being questioned [23-25].

A recent study [1] surveyed Vietnamese business students and working adults to examine their ethics scores and concluded that students had a significantly higher level of moral maturity. For Saudi Arabian students, no such studies are found in the academic literature using PBES and other relevant ethical dilemmas. As a result, we think it would be interesting to investigate the ethical decision-making of students in Saudi Arabia.

Throughout the globe, the continuous increase of ethical problems related to business has been poorly handled as a 
result of recent corporate scandals, for example, the series of bribery scandals at Siemens, a Hewlett-Packard (HP) spying scandal [26], and serious corruption scandals in other organizations around the globe. Thus, it is necessary that decisionmakers receive adequate ethical education and training to make themselves more capable of dealing with difficult ethical problems in the future [24].

An effective ethics education program should be encouraged and integrated into the curriculum because an appropriate ethical education is meant to reflect on one's actions, and is an important prerequisite guide for sustainable future behavior [27, 28]. In the business ethics literature, the attention has been devoted to increase business student awareness of corporate social responsibility issues. As has already been demonstrated, many recently published studies seem to stress the importance of the educational training to include business ethics courses in college curriculums so students can handle complex ethical decision making [29]. Many studies have endeavored to improve instruction in ethics by encouraging changes in curriculum content and teaching method for business schools [30].

Some empirical work has focused on the relative influences of personal ethical ideologies, the perception of an ethical problem, perceived importance of ethics, and gender on the ethical intentions of business students [31, 32]. However, little research has been conducted concerning Arab students' awareness of ethics regarding their ethical decision choices. In general, just like everyone else, Arab students will become decision-makers and will encounter a complex business environment in the future. Thus, there is a need to understand the perceptions and decision processes behind the ethical/unethical decision making behavior of these students because ethical perceptions and the decision processes of decision-makers are vital to any organization.

Saudi Arabia is an Arab regional power where it is the world's largest oil producer and exporter and maintains the largest proven reserves of crude oil, equal to 25.5 per cent of the world's total [33]. The country has a population of almost 29 million [34] and a per capita income of US $\$ 25,700$ [35]. About $90 \%$ of the citizens are Arabs. The remaining $10 \%$ is composed mostly of Africans and/or Asians [22]. The social and cultural characteristics of the country differ very much from those of industrialized Western nations. Saudi Arabia in particular is a conservative country where Islamic teachings and Arabian cultural values are dominant. There is a sharp division of labor between men and women, and there exists a widely practiced segregation of the genders in many public roles. Therefore, there are rigid boundaries in social roles and expectations for women compared to men in the country and thus there are fewer women in Saudi workforce (8.1\%) [36]. Finally, Saudi Arabia's culture manifests high power distance, high uncertainty avoidance, collectivist, and femininity characteristics along Hofstede's [37] cultural dimensions [38, 39].

Being an Islamic country where people have strong religious values, their moral development is naturally influenced by their spiritual conditioning. Moral development, according to researchers $[16,40]$, is the growth or ability of an individual to distinguish right from wrong, to develop a framework of ethical values, and to learn to act morally [3].
Some authors [41] have explained that the term development is usually associated with progressive and continuous changes that take place as a result of learning and experience from the beginning of a person's life until death. Researchers claim that moral development occurs through the process of not only life maturity but socialization in the community, workplace, and educational institutions as well [24]. Others [42] state that science, religion, culture, standards of good and bad, and other forms of behaviour in society are passed on by nurture (that is, they are learned) and not by nature. Many researchers [43] believe that each individual has the ability to think about his or her very thought process, called "self-awareness", and this enables us to make significant advances from generation to generation. Consequently, moral character is an aspect of personality which can structure a person's moral, ethical, and personal beliefs. Similar to other authors [44], we believe that a person may be deemed moral when he/she behaves ethically; as such, moral behavior is a function of one's past experience with similar situations in which a person has learned to behave in an ethical and a socially responsible manner [16].

Ethics principles, which are defined as the disciplines dealing with what is good and bad and with moral duty and obligation, have deep roots in the Arab and Middle Eastern cultures [41]. Ethical dilemmas are often studied in primary and college level curriculums as to better prepare future leaders for the challenges they will face in the workplace. This study looks at college students in Saudi Arabia to explore their ethical maturity based on various demographic variables.

\section{RESEARCH METHODOLOGY AND ANALYSIS}

The sample for this study is university undergraduate students in the business or management program of a local public university in the city of Madinah, Saudi Arabia. Although we recognize both the value and limitations of this survey group [45], given that business students today are the business leaders of tomorrow, and coupled with the negative stereotypes surrounding them, we believe the issue of business ethics is a cause for concern for this group [46, 47].

In measuring the students' business ethics perception, we used Clark and Clark's [48] Personal Business Ethics Score (PBES) instrument. Institutional Review Board (IRB) approval was requested at the second author's institution for a cross-cultural study on this topic using an online platform for the survey, where one researcher's contact information along with a description of the study was presented that this study is voluntary, confidential, and participants are not required to complete it. This PBES instrument has successfully been used by previous scholars such as Freedmen [49] and $\mathrm{Mu}-$ jtaba [30] to a sample of executives and managers in the United States. More recently, many scholars [41] have used the instrument to measure the business ethics perceptions of public and private employees in Iran.

The questionnaires were administered in one sitting, without prior notice and with no opportunity for respondents to consult or discuss their responses with others. The students were selected based on their enrollment with the 'English medium' classes or in other words - taught by English speaking only instructors. The 'English medium' cohort or classes was relatively new in the business program. There- 
fore, the students' number was relatively small as compared to the Arabic cohort. Based on the English cohort population of 300 students (150 males and 150 females), the questionnaires were administered by the course instructor during class time. Participation was voluntary and students were given course credit for completing the survey. The course credit awarded was minimal (1 mark toward the midterm exam). Although the students may be biased in participating in the survey, there was no indication of bias in the results. This is evident from the variance observed in the PBES measure. The respondents were informed that all replies would be kept for statistical purposes only and the responses would be kept strictly confidential. They were also informed that they would not need to identify themselves personally.

Initially, the English version of the questionnaire was given to the students. However, it was found that some students faced difficulty in answering the questionnaire due to poor level of English proficiency and the 'foreign' examples in the ethical scenarios. Coherently, we decided to have it translated to Arabic. We follow the back translation as suggested by previous researchers [50]. The original English version of the survey was translated by the third author, who is a native speaker into Arabic. The Arabic questionnaire was then translated to English by a university professor who spoke both languages fluently. The authors and the professor then looked at the translated version to see if the meaning of the survey dilemmas and questions remained the same as in the original English version. They were satisfied that there were no major differences of the two versions of the questionnaire (English and Arabic).

The first part of the questionnaire comprises of demographic details such as gender, age, semester, academic major followed by questions asking whether they have management experience and their awareness of ethics either within their previous organization, existing institution or by attending a course or seminar. The second part of the questionnaire which is the dependent variable comprises of eleven ethical scenarios measuring the PBES [See 3]. Therefore, the questionnaire encompasses of 21 items and the survey takes an average total time of 20 minutes to complete. As expected, the PBES scenario questions consumed the most time, even though it has only 11 items.

\section{SAMPLE DESCRIPTIVE STATISTICS}

Based on the initial target of 300 students, a total of 189 questionnaires were collected comprising a response rate of $63 \%$. The 'poor-than-expected' response was due to the procrastination habit of some of the students that failed to hand in the questionnaire during class time, absenteeism and their unwillingness to participate in the study. The response rate was worse in the female students $(48 \%)$ compared to the male students $(61 \%)$ due to "accessibility issues". In the Saudi Arabia, the students are segregated based on gender. Male instructors are now allowed to teach or enter the female 'sections' and class consists of entirely either male or female students separated by gender. Thus, although Saudi Arabia is known as a patriarchal society based on most daily activities, normally the male conducts most professional or workrelated activities - this study has made an attempt to have an almost 'equal' representation where the final sample consists of $56 \%$ male and $44 \%$ female.
Out of the 189 completed questionnaires, a total of 25 surveys were discarded due to the fact that some sections of the questionnaires were not complete. Analysis of missing data revealed that no single variable exceeded the 15 percent threshold of missing values; i.e. the point at which one should consider deletion of the variable or case. Missing values were in the range of $0-2.5$ percent per variable. When examining missing values within the cases(i.e. observations), it was found that among the cases that had missing data, most of them were missing only few values.

Consequently, descriptive statistics, means, standard deviations, and Pearson's correlation were obtained. Of the respondents, there were $92(56.1 \%)$ male respondents and the rest were female $(43.9 \%)$. Over $90 \%$ of the respondents are less than 24 years old where they are currently within the freshman and sophomore year. In terms of academic major, more than $50 \%$ of the respondents put their major as others while the next two majors; business administration and MIS have an equal representation of $22 \%$ each. The sample characteristics are representable of the college of business administration population as the business college is relatively new. The majority of the students in the college program are in business administration and MIS.

With regards to the students' exposure in management and business ethics, the sample revealed that, in general, their exposure is minimal. This can be seen where an overwhelming majority of the respondents $(83 \%)$ do not have any experience working in a management position. Almost three-quarters of the respondents noted that they had not taken an ethics course, nor attended an ethics training (87\%) nor were aware that the current institution (the university) has a code of ethics $(75 \%)$. Finally, almost all the students have not attended any sensitivity training. Nevertheless, about half of the respondents $(42 \%)$ have enrolled in law course (subject). Based on the above result, it is likely that the questions regarding the ethical scenarios in the questionnaire are something 'new' to these students. Table 1 illustrates the descriptive statistics of the sample.

\section{FACTOR ANALYSIS}

Before conducting a factor analysis, it is necessary to check sampling adequacy and sphericity to determine whether if it is worth proceeding with the analysis. According to Kaiser [51], KMO (Kaiser-Meyer-Oklin) is used to test whether the variables in this study sample are adequate to correlate. A general rule of thumb is that a KMO value should be greater than 0.5 for satisfactory factor analysis to proceed. For this study, the initial KMO was 0.743 for business ethics; therefore, we proceed with factor analysis. Using principal components analysis and varimax rotation, variables with low factor loadings $(<0.5)$ were considered for deletion, as were variables loading significantly $(>0.3)$ onto more than one factor. The communalities of the variables, representing the amount of variance accounted for the factor solution of each variable, were also examined. Factors with low communalities $(<0.4)$ were also considered for deletion. Several other complementary methods were employed to obtain the most representative and parsimonious set of components such as eigen values more than 1 and scree plot. 
Table 1. Descriptive statistics of the sample $(n=164)$.

\begin{tabular}{|c|c|c|c|c|}
\hline \multicolumn{5}{|l|}{ Gender } \\
\hline Female $=2$ & 72 & 43.9 & & \\
\hline \multicolumn{5}{|l|}{ Age } \\
\hline $22-24=2$ & 75 & 45.7 & & \\
\hline $25-27=3$ & 13 & 7.9 & & \\
\hline More than $28=4$ & 3 & 1.8 & & \\
\hline \multicolumn{5}{|l|}{ Semester } \\
\hline Junior & 20 & 12.8 & & \\
\hline Senior & 22 & 14.1 & & \\
\hline \multicolumn{5}{|l|}{ Major } \\
\hline Accounting $=1$ & 4 & 2.4 & 4.76 & 1.405 \\
\hline Finance $=2$ & 0 & 0 & & \\
\hline Business Administration $=3$ & 36 & 22.0 & & \\
\hline $\mathrm{MIS}=4$ & 37 & 22.6 & & \\
\hline Marketing $=5$ & 1 & 0.6 & & \\
\hline Yes $=1$ & 36 & 25.2 & 1.75 & 0.436 \\
\hline $\mathrm{No}=2$ & 107 & 74.8 & & \\
\hline \multicolumn{5}{|l|}{ Ethics course } \\
\hline Yes $=1$ & 51 & 31.1 & 1.69 & 0.464 \\
\hline $\mathrm{No}=2$ & 113 & 68.9 & & \\
\hline \multicolumn{5}{|l|}{ Law course } \\
\hline Yes $=1$ & 69 & 42.1 & 1.58 & 0.495 \\
\hline $\mathrm{No}=2$ & 95 & 57.9 & & \\
\hline \multicolumn{5}{|l|}{ Ethics training } \\
\hline Yes $=1$ & 21 & 13 & 1.87 & 0.337 \\
\hline $\mathrm{No}=2$ & 141 & 87 & & \\
\hline \multicolumn{5}{|l|}{ Sensitivity training } \\
\hline Yes $=1$ & 12 & 7.4 & 1.93 & 0.263 \\
\hline $\mathrm{No}=2$ & 150 & 92.6 & & \\
\hline & & & & \\
\hline
\end{tabular}


Table 2. KMO and Bartlett's test results.

\begin{tabular}{|c|c|c|c|c|}
\hline Variables & Kaiser-Meyer-Olkin measure of sampling adequacy & & KMO and & Bartlett's test \\
\hline \hline & & $\begin{array}{c}\text { Approx. } \\
\text { Chi-square }\end{array}$ & Sig. \\
\hline Ethics & 0.773 & 215.610 & 28 & 0.000 \\
\hline
\end{tabular}

Table 3. Results of factor analysis and reliability test.

\begin{tabular}{|c|c|c|c|c|}
\hline Factor constructs and items & Factor loading & Eigenvalue & Alpha if item deleted & Cronbach's alpha \\
\hline \hline ETHICS04 & 0.640 & 2.860 & 0.696 & 0.699 \\
\hline ETHICS05 & 0.624 & 0.731 \\
\hline ETHICS06 & 0.580 & & 0.689 & 0.674 \\
\hline ETHICS07 & 0.661 & 0.731 & 0.725 \\
\hline ETHICS08 & 0.712 & & 0.706 \\
\hline ETHICS09 & 0.441 & & \\
\hline ETHICS010 & 0.503 & & & \\
\hline
\end{tabular}

The results of the factor analysis showed that the first three of the eleven PBES scales were distributed into three dimensions with multiple cross-loadings. Therefore, the items were deleted and the scales were subjected to another round of factor analysis. The KMO score for the new analysis is 0.773 with an overall cumulative score of 35.752 percent on a single component. Table 2 shows the KMO and Bartlett's test score while Table $\mathbf{3}$ illustrates the result of the factor analysis for PBES for this study. Subsequently, reliability analysis was done on all the remaining eight measurement items which gave a cronbach's alpha score of 0.731 which exceeds the recommended score of 0.7 [52]. Although the measurement items for this study comprised of only eight items from the original eleven items, the cronbach alpha was almost equivalent as to the recent study conducted by [3] which is at 0.7627 .

Upon acquiring the construct validity and reliability, a correlation analysis of all the variables were carried out to put the substantive findings into context. Pearson's correlation for each of the variables under study is listed in Table 4 where the correlation coefficients (r) that reach statistical significance level are noted at the end of the table. Based on the results, it is evident that there were significant differences between seniority, management exposure, legal knowledge, as well as sensitivity and ethics training.

\section{HYPOTHESIS TESTING AND FINDINGS}

Upon satisfaction that appropriate purification procedures have been conducted on all the variables under study, the subsequent process involves testing the proposed relationship of each hypothesis. To begin with, the study used $t$ test and analysis of variance (ANOVA) to compare differences of the means for independent variables (i.e. age, seniority, management and ethical exposure) on the dependent variable (personal business ethics). The probability level of significance for $t$ test and ANOVA analysis at the $\mathrm{p}<0.05$ level of significance is used to determine if there are differences in the responses of the students based on age, seniority, management, legal and ethics exposure.

Based on the suggested threshold, there were no statistically significant differences for the variables under study. For instance, none of the demographic characteristics such as gender $($ male $=3.68 \pm .648$; female $=3.77 \pm .626)$, age $($ less than $21=3.68 \pm .636 ; 22-24=3.74 \pm .654$ ) and seniority (freshman and sophomore $=3.75 \pm .628$; junior and senior $=3.76 \pm .570)$ meet the suggested significance level. Although the results seem disappointing, it may be well expected. The number of students that were exposed to ethics either through course enrollment, seminar or sensitivity training was overwhelmingly low. In other words, most of the students do not have any managerial experience, ethical, or legal knowledge. Nevertheless, the $t$ test and ANOVA analysis only reveal whether there is a significant difference of means between groups. As such, it has limited explanation power to discuss. Tables 5 and $\mathbf{6}$ present the results of the study for $t$ test and ANOVA.

\section{MULTIPLE REGRESSION ANALYSIS RESULTS}

The following paragraphs discuss the results of the hypothesis testing based on the stepwise multiple regression analysis. While the earlier analysis looks at whether there was a significant difference of means between the groups, the following analysis tested the effects of the independent factors on the dependent factor. This analysis is designed to find the most parsimonious set of predictors that are most effective in predicting the dependent variable by identifying 
Table 4. Correlation between independent and dependent variables.

\begin{tabular}{|c|c|c|c|c|c|c|c|}
\hline Age & 1 & & & & & & \\
\hline Mgt Exp. & $-.445^{* *}$ & $-.471 * *$ & 1 & & & & \\
\hline Legal knowledge & $-.331 * *$ & $-.412 * *$ & $.171^{*}$ & 1 & & & \\
\hline Sensitivity training & -.062 & -.062 & $.307 * *$ & .042 & $.593 * *$ & 1 & \\
\hline Ethics & 0.073 & .047 & .021 & -.122 & -.107 & -.080 & 1 \\
\hline
\end{tabular}

*Correlation is significant at the 0.05 level (two-tailed)

** Correlation is significant at the 0.01 level (two-tailed)

Table 5. The mean and standard deviation of each variable in various groups.

\begin{tabular}{|c|c|c|c|}
\hline Variables & $\mathbf{N}$ & Mean & SD \\
\hline $\begin{array}{l}\text { Gender } \\
\text { Male } \\
\text { Female }\end{array}$ & $\begin{array}{l}92 \\
72\end{array}$ & $\begin{array}{l}3.686 \\
3.777\end{array}$ & $\begin{array}{l}.648 \\
.626\end{array}$ \\
\hline $\begin{array}{c}\text { Age } \\
\text { Less than } 21 \\
22-24\end{array}$ & $\begin{array}{l}73 \\
75\end{array}$ & $\begin{array}{l}3.679 \\
3.736\end{array}$ & $\begin{array}{l}.636 \\
.654\end{array}$ \\
\hline $\begin{array}{c}\text { Management Experience } \\
\text { Yes } \\
\text { No }\end{array}$ & $\begin{array}{c}28 \\
136\end{array}$ & $\begin{array}{l}3.696 \\
3.732\end{array}$ & $\begin{array}{l}.566 \\
.653\end{array}$ \\
\hline $\begin{array}{c}\text { Taken Business Ethics Course } \\
\text { Yes } \\
\text { No }\end{array}$ & $\begin{array}{c}51 \\
113\end{array}$ & $\begin{array}{l}3.767 \\
3.708\end{array}$ & $\begin{array}{l}.663 \\
.059\end{array}$ \\
\hline $\begin{array}{c}\text { Taken Business Law Course } \\
\text { Yes } \\
\text { No }\end{array}$ & $\begin{array}{l}69 \\
95\end{array}$ & $\begin{array}{l}3.817 \\
3.661\end{array}$ & $\begin{array}{l}.633 \\
.636\end{array}$ \\
\hline $\begin{array}{c}\text { Attend Ethics Training } \\
\text { Yes } \\
\text { No }\end{array}$ & $\begin{array}{c}21 \\
141\end{array}$ & $\begin{array}{l}3.893 \\
3.691\end{array}$ & $\begin{array}{l}.613 \\
.637\end{array}$ \\
\hline $\begin{array}{c}\text { Attend Sensitivity Training } \\
\text { Yes } \\
\text { No }\end{array}$ & $\begin{array}{c}12 \\
150\end{array}$ & $\begin{array}{l}3.896 \\
3.703\end{array}$ & $\begin{array}{l}.721 \\
.629\end{array}$ \\
\hline
\end{tabular}

the subset of independent variables that has the strongest relationship to a dependent variable. Stepwise regression essentially does multiple regressions a number of times, each time removing the weakest correlated variable. At the end, the variables that explain the best distribution are left for analysis. This permits one to understand the relative degree of influence of several independent factors on a dependent factor. The minimum ratio of valid cases to independent variables for stepwise multiple regression is 5 to 1 . With 164 valid cases and eight independent variables the ratio for this analysis is 20.5 to 1 , which satisfies the minimum requirement. The item "does your institution have a code of ethics" was excluded in the analysis as the question did not have 'relevance' to the student's demographic profiles nor the ethical knowledge background (through enrolling in course, seminars or work experience). Nevertheless, since the ratio of 20.5 to 1 does not satisfy the preferred ratio of 50 to 1 , a caution should be added to the interpretation of the analysis. 
Table 6. The results of Levene's test and t test on dependent variable.

\begin{tabular}{|c|c|c|c|c|}
\hline & $\mathrm{F}$ & $\mathrm{p}$ & $t$ & $\mathrm{p}$ \\
\hline Age & .087 & .769 & -.536 & .593 \\
\hline College Years & .871 & .352 & -.031 & .975 \\
\hline Existence of Code of Ethics & .093 & .760 & -.269 & .789 \\
\hline Ethics Knowledge & .269 & .605 & .549 & .584 \\
\hline Legal Knowledge & .267 & .606 & 1.558 & .121 \\
\hline
\end{tabular}

Table 7. The results of stepwise multiple regression analysis.

\begin{tabular}{|c|c|c|c|c|c|c|c|}
\hline Model & $\mathbf{R}^{2}$ & Adj- $R^{2}$ & Standard Coefficient & $\mathbf{t}$ & Significant & Collinearity & Statistics \\
\hline Legal knowledge & & & & -2.256 & $.026^{*}$ & & \\
\hline
\end{tabular}

Dependent Variable: Personal Business Ethics

All other independent variables were excluded in the stepwise analysis. Only legal knowledge is analyzed in the model. $* * * \mathrm{p}<0.001 ; * \mathrm{p}<0.05$

The results of the stepwise multiple regression showed that legal knowledge (through an enrollment in a business law course) proves to have a significant relationship with PBES. The overall coefficient of the regression was $\mathrm{R}^{2}=0.032$ Adj $-\mathrm{R}^{2}=0.026$, and Durbin - Watson $=1.752$ (within the accepted range of 1.5-2.5), shows no autocorrelation within variables. Variance Inflation Factor (VIF) of each variable is below ten which shows no multicollinearity between each independent variable and dependent variable. The overall regression model suggested that legal knowledge ( $\beta=-.180, p<.0001)$ has the ability to predict the dependent variable alone. This suggest that legal knowledge $(\mathrm{F}=5.089$, $\mathrm{p}=0.026<0.05$ ) has a statistically significant association with personal business ethics.

However, since the standardized coefficient ( $\beta$ ) was negative, indicating an inverse relationship in which higher numeric values for legal knowledge are associated with lower numeric values for PBES, an investigation of the data coding was done to ensure correct interpretation. The variable for enrollment in business law is coded as a dichotomous scale (Yes $=1$, No $=2$ ) where else the PBES score was coded in a Likert scale with a higher values indicating strongly disapprove (Strongly Approve $=1$ to Strongly Disapprove $=5$ ) . Therefore, the negative value of $\beta$ implies that the students who took business law tend to disapprove the ethical scenarios in the questionnaire. In other words, students who have a legal knowledge tend to have a higher personal business ethics score (more ethical). With regards to all the other predictors, age, seniority, management exposure, ethical course or sensitivity training, they do not show any significant relationship and were dropped from the analysis. Table 7 illustrates the results of the stepwise multiple regression.

\section{LIMITATIONS AND RECOMMENDATIONS FOR FUTURE RESEARCH}

A few limitations of this study need to be noted to put the findings into perspective. First, our sample is limited to business school students. As noted in previous studies [45], the value attitudes of college students are valuable though not exclusive resources for research. Therefore, future studies should include a more conclusive representation of students from various programs or populations. The research also covers students at a single academic institution, in a specific location and is almost entirely of a single ethnicity (Arab). Although there are no apparent reasons to suggest that the results of the students in this part of the region would differ meaningfully from those of their counterparts in other Middle-Eastern regions (e.g. Eastern or Northern region), further research is required to establish whether the results of this study are generalizable over a wider geographic area. A wider perspective would be to replicate this study to see if results generalize to student groups elsewhere in other regional countries and cultures. Finally, all data were collected using self-reported questionnaires raising the possibility of response set and social desirability bias - though this was not found in our study. Therefore, to mitigate for these possible effects, future research should address the longitudinal effects of similar ethics interventions on students' ethical ma- 
turity scores to assess the lasting impact of such interventions. Furthermore, future researchers can look at the applicability of these results into large organizations operating in Saudi Arabia for training and development purpose.

\section{CONCLUSION}

The main aim of this research was to test the students' demographic profiles and 'ethical exposure' in relationship with PBES using existing measures developed in the western culture. This research is in accordance with previous studies that have tested the instruments with the student population in different parts of the world. However, while other studies provided some insights on the significant relationships of the various predictors of PBES, this study managed to highlight the relevance of business law and ethical maturity. All the predictors proposed in this study such as gender, age, seniority and ethical exposure through courses, seminars or work experience did not show any significant effects towards ethical maturity. A plausible reason might be due to the majority of the respondents did not have such exposure or enrolled in any of the courses or training. In addition, the original eleven PBES measurement items were reduced to eight items due to issues highlighted in the analysis. Therefore, it is difficult to compare the findings of this study with studies done elsewhere [e.g. 3, 49, 53].

Nevertheless, this study highlights an important issue that needs to be given attention. Based on the descriptive findings, it was evident that a majority of the students were not exposed to ethics or sensitivity training. This may lead to detrimental effects as substantiated in previous studies where it may influence one's level of ethical maturity, and this is certainly a grave concern. Therefore, business school deans should pursue the American Assembly of Collegiate Schools of Business (AACSB) 'mandate' that require ethics to be incorporated into business curricula [54]. We believe that by giving the appropriate ethical foundation, it will provide a crucial step towards a commitment to develop ethical and socially responsible business practices.

\section{ABOUT AUTHORS}

Abdul R. A. Bakar* is an assistant professor at Prince Sultan University, Saudi Arabia. He holds a PhD in Strategic Marketing from Aston University, United Kingdom. His current research interests focus in strategic marketing, adoption and diffusion of technology, internationalization and customer value. His recent publications appear in journals such as Emerald Emerging Markets Case Studies, Journal of Organizational Change Management and Journal for Global Business Advancement. He can be contacted by email atdrrahimbakar@gmail.com or at: Aabubakar@psu.edu.sa

Dr. Bahaudin G. Mujtaba is professor of management, international management, and human resources at Nova Southeastern University's H. Wayne Huizenga School of Business and Entrepreneurship in Fort Lauderdale, Florida of USA. Over the past three decades, Bahaudin has served as manager, trainer, and management development specialist in the corporate world as well as a director, department chair and faculty member in academia. He has served as a visiting professor in several schools across the globe including the
United States, Jamaica, Brazil, Bahamas, Grenada, Thailand, Vietnam, China, and Pakistan. His areas of research are business ethics, cross-cultural leadership, and diversity management. Bahaudin can be reached through email at: mujtaba@nova.edu

Ahmed Medjedel currently chairs the marketing department at the College of Business Administration, Taibah University in Madina, Saudi Arabia. With a background of development economics from Leeds University, United Kingdom he continued his studies and graduated with a DBA from the University of Algiers in 2004. His research interests is in eMarketing, consumer behavior and knowledge management. Dr. Medjedel can be contacted at aamgdal@taibahu.edu.sa or: medjedel@yahoo.com

\section{CONFLICT OF INTEREST}

The authors confirm that this article content has no conflict of interest.

\section{ACKNOWLEDGEMENTS}

Declared none.

\section{REFERENCES}

[1] Nguyen LD, Mujtaba BG, Tran CN, Tran QHM. Sustainable growth and ethics: a study of business ethics in vietnam between business students and working adults. Southeast Asian J Manage 2013; 7(1): 41-56.

[2] Chen LY, Mujtaba BG, Heron TW. Utilizing computer-based scenarios to explore idealism and relativism influences on perceptions of Ethics and Social Responsibilities and ethical decision making. Int J Bus Govern Ethics 2011; 6(4): 359-84.

[3] Mujtaba BG, Tajaddini R, and Chen LY. Business ethics perceptions of public and private sector iranians. J Bus Ethics 2011; 104(3): 433-47.

[4] Bodkin CD. University students' perceptions regarding ethical marketing practices: Affecting change through instructional techniques. J Bus Ethics 2007; 72(3): 207.

[5] O'Fallon MJ, Butterfield KD. A review of the empirical ethical decision-making literature: 1996-2003. J Bus Ethics 2005; 59(4): 375-413.

[6] Ford RC. Ethical decision making: a review of the empirical literature. J Bus Ethics 1994; 13(3): 205.

[7] Villa JS. The Ethical Stance in Banking. Doktorgrades der Philosophie, Universiät München, den Philippinen 2010.

[8] Safakli OV. Ethical perceptions of customers towards the services of foreign branch banks in northern cyprus. J Appl Sci 2007; 7(2): 294.

[9] Božović J. Business ethics in banking. Facta universitatis-series. Econ Org 2010 ; 4(2): 173-82.

[10] Putnis J. The Banking regulation review London, UK: Law Bus Resear 2010.

[11] Icke BT, Caliskan E N, Ayturk Y, Icke MA. An empirical research of ethical banking in Turkey. J Math Anal Appl 2011; 7(3): 289304.

[12] Krishnan AR, Sulphey M. Does cadre difference and certain demographic factors influence ethical orientation: a study among bank personnel. Saaransh RKG J Manage 2009; 1(1): 60.

[13] Dogarawa AB. An examination of ethical dilemmas in the nigerian banking sector. SSRN eLibrary 2006.

[14] Carse. The importance of ethics in banking: Keynote address in international conference on banking ethics, Hong Kong 1999.

[15] Boatright JR. Finance ethics: critical issues in theory and practice. Wiley 2010; p. 592.

[16] Mujtaba BG. Business ethics of retail employees: How ethical are modern workers? Florida: ILEAD Academy Publications 2010.

[17] Nguyen LD, Mujtaba BG, Tran QHM, Tran CN. Cross-culture management: an empirical examination of task and relationship 
orientations of Omani and the Vietnamese. Int J Bus App Sci 2013; 2(1): 64-84.

[18] Kannaiah D, Kumar N. Research note an urgent need for ethics education for accountants. Issues Soc Environ Accounting 2012; 3(1): 88-94.

[19] Frisque DA, Kolb JA. The effects of an ethics training program on attitude, knowledge, and transfer of training of office professionals: A treatment-and control-group design. Hum Res Dev Q 2008; 19(1): 35-53.

[20] Sims RR, Felton EL. Designing and delivering business ethics teaching and learning. J Bus Ethics 2006; 63(3): 297-312.

[21] Mujtaba BG, Cavico FJ, McCartney TO, DiPaolo PT. Ethics and retail management professionals: an examination of gender, age, education, and experience variables. Am J Bus Educ 2009; 2(3): 13-26.

[22] Mujtaba BG. Cross cultural management and negotiation practices. Florida: ILEAD Academy 2007.

[23] Murphy JE. Faculty and student perceptions of business ethics education at an undergraduate institution. Capella University 2012.

[24] Mujtaba B, Sims RL. Socializing retail employees in ethical values: the effectiveness of the formal versus informal methods. J Bus Psychol 2006; 21(2): 261-72.

[25] Rabins MJ. Teaching engineering ethics to undergraduates: Why? What? How? Sci Eng Ethics 1998; 4(3): 291-302.

[26] Cavico FJ, Mujtaba BG. Mujtaba Business Ethics: the moral foundation of leadership, management, and entrepreneurship, $3^{\text {rd }}$ ed. Boston: Pearson Custom Publications 2013.

[27] Kaifi BA. Human resource management: an applied approach. Tamarac: Llumina Press 2014.

[28] Mujtaba BG. Managerial skills and practices for global leadership. Florida, Davie: ILEAD Academy 2014.

[29] Felton EL, Sims RR. Teaching business ethics: targeted outputs. J Bus Ethics 2005; 60: 377-91.

[30] Mujtaba BG. Business ethics survey of supermarket managers and employees. UMI Dissertation Service. A Bell \& Howell Company 1997.

[31] Marta JK, Attia A, Singhapakdi A, Atteya N. A comparison of ethical perceptions and moral philosophies of American and Egyptian business students. Teach Bus Ethics 2003; 7: 1-20.

[32] Singhapakdi A. Important factors underlying ethical intentions of students: Implications for marketing education. J Mark Educ 2004; 26: 261-70.

[33] Almunajjed M. Saudi women speak: 24 remarkable women tell their stories. $1^{\text {st }}$ ed. Arab Institute for Research and Publishing, Beirut 2006.

[34] World Bank (2012). Available at http://data.worldbank.org/country/ saudi-arabia [accessed 16 October 2013].
[35] Arabnews 6 September (2013). Available at http://www.arabnews.com/ news/463668 [accessed 16 October 2013].

[36] Saudi Arabian Monetary Agency (SAMA). Forty-Fourth Annual Report. Research and Statistics Department, Riyadh 2008.

[37] Hofstede G. Culture's consequences: international differences in work-related values. Sage, Beverly Hills, CA 1980.

[38] Al-Khaldi MA, Wallace RS. The influence of attitudes on personal computerutilization among knowledge workers: the case of Saudi Arabia. Info Manage 1999; 36(1): 185-204.

[39] Robertson CJ, Al-Khatib JA, Al-Habib M, Lanoue D. Beliefs about the work in the Middle East and convergence versus divergence of values. J World Bus 2001; 36 (3): 223-44.

[40] Rich JM, DeVitis LJ. Theories of moral development. $2^{\text {nd }}$ ed. Charles Thomas Publishing 1994.

[41] Mujtaba BG, Tajaddini R, Chen LY. Perceptions of Ethics by Public and Private Sector Iranians. Asian J Bus Manage Sci 2011; 1(2): 104-18.

[42] Kuper L. Race, science and society. The Unescor Press and Columbia University Press 1975.

[43] Covey RS. The 7 habits of highly effective people: powerful lessons in personal change. New York: First Fireside Edition 1990.

[44] Fritzche DJ. Personal values: Potential keys to ethical decision making. J Bus Ethics 1995; 14: 909-22.

[45] Greenberg J. The college sophomore as guinea pig: Setting the record straight. Acad Manage Rev 1987; 12(1): 157-9.

[46] Springett D, Kearins K. Gaining legitimacy? Sustainable development in business school curricula. J Sust Dev 2001; 9: 213-21.

[47] Thomas TE. Are business students buying it? A theoretical framework for measuring attitudes toward the legitimacy of environmental sustainability. Bus Strateg Environ 2005; 14: 186-97.

[48] Clark JW, Clark SJ. Religion and moral standards of American businessmen. Cincinnati: Southwestern Publishing Co1966.

[49] Freedman, A. Business ethics survey of hospitality students and managers. DBA Dissertation. Nova Southeastern University 1990.

[50] Ercikan K. Translation effects in international assessments. International Journal of Educational Research 1998; 29: 543-53.

[51] Kaiser HF. An index of factorial simplicity. Psychometrika 1974; 39(1): 31-6.

[52] Nunnally JC, Bernstein IH. Psychometric theory. New York: McGraw 1994.

[53] Wynd WR, Mager J. The business and society course:Does it change student attitudes? J Bus Ethics 1989; 8(6): 486-91.

[54] American Assembly of Collegiate Schools of Business (AACSB). Accreditation council policies, procedures and standards. St. Louis, MO: American Assembly of Collegiate Schools of Business 1987.

Received: February 02, 2015

Revised: March 09, 2015

Accepted: March 11, 2015

(C) Abu Bakar et al.; Licensee Bentham Open.

This is an open access article licensed under the terms of the Creative Commons Attribution Non-Commercial License (http://creativecommons.org/licenses/by-nc/3.0/) which permits unrestricted, non-commercial use, distribution and reproduction in any medium, provided the work is properly cited. 